\title{
Behavioral, Physiological, and Neuroendocrine Stress Responses and Differential Sensitivity to Diazepam in Two Wistar Rat Lines Selectively Bred for High- and Low-Anxiety-Related Behavior
}

Gudrun Liebsch, M.S., Astrid C.E. Linthorst, Ph.D., Inga D. Neumann, Ph.D., Johannes M.H.M. Reul, Ph.D., Florian Holsboer, M.D., Ph.D., and Rainer Landgraf, Ph.D.

Two Wistar rat lines, selectively bred for high-anxietyrelated behavior $(H A B)$ and low-anxiety-related behavior $(L A B)$ in the elevated plus-maze test, were tested for the susceptibility of their behavioral characteristics to anxiolytic treatment and for their endocrine and physiological reactivity to different stressors. Injection of $1 \mathrm{mg} / \mathrm{kg}$ diazepam failed to affect line differences in coping strategy but resulted in a marked (20-fold) decrease in plusmaze anxiety in $H A B$ rats; whereas, the anxiolytic effect was less pronounced in $L A B$ animals. Biotelemetrical measurements revealed that $H A B$ and $L A B$ rats do not significantly differ in their baseline body temperature, locomotor activity, food and water intake, or in stressinduced alterations of the diurnal rhythms in these parameters. However, line differences were found in acute changes in body temperature and locomotor activity following stress exposure, $L A B$ rats responding with a greater, albeit shorter, increase in body temperature and activity than HAB animals. Basal ACTH and corticosterone plasma levels as well as pituitary reactivity to intravenously administered CRH $(40 \mathrm{ng} / \mathrm{kg})$ were similar in both lines, although, especially in response to plus-maze exposure, $H A B$ rats tended toward higher ACTH secretion than $L A B$ rats. These data confirm that animals with high or low basal levels of anxiety may be a promising model for studying the mechanisms of action of anxiolytic substances. Nevertheless, the endocrine findings support the notion that the reactivity of the hypothalamo-pituitary-adrenocortical system and anxiety-related behavior can be regulated independently. [Neuropsychopharmacology 19:381396, 1998] (c) 1998 American College of Neuropsychopharmacology. Published by Elsevier Science Inc.
KEY WORDS: Emotionality; Stress coping; HPA system, Elevated plus-maze; Forced swim test; Benzodiazepines; Biotelemetry

From the Max Planck Institute of Psychiatry, Munich, Germany Address correspondence to: Dr. R. Landgraf, Max Planck Institute of Psychiatry, Kraepelinstr. 2, 80804 Munich, Germany.

Received January 15, 1997; revised March 25, 1998; accepted April $16,1998$.
Genetic factors contribute to the high interindividual variability in type and/or intensity of the behavioral, neuroendocrine, and physiological stress responses observed in various species, including humans and laboratory rats (Boissy 1995; Clément et al. 1997; Cools et al. 1990; Curé and Rolinat 1992; Prasad et al. 1996; 1997; Spanagel et al. 1995; Tesser 1993; Zuckerman 1993). This fact has been used as the basis for selective bidirectional breeding programs from which strains and lines differing in their behavioral and/or neuroendocrine re- 
sponses to environmental challenges have emerged (Brush 1991; Castanon and Mormède 1994; Cools et al. 1993; Gentsch et al. 1988; Walker et al. 1992). Recently, we reported the establishment of two Wistar rat lines selectively bred for differing behavioral performances in the elevated plus-maze test, now termed high-anxiety-related behavior (HAB) and low-anxiety-related behavior (LAB) lines, respectively (Liebsch et al. 1998). This animal model of inborn anxiety provides the advantage of avoiding conditioned stimuli that by themselves are likely to trigger behavioral, neuroendocrine, and physiological alterations. Interestingly, the HAB and LAB animals also prefer different coping strategies in a forced swim test (Liebsch et al. 1998), pointing toward a link between anxiety and coping with stressful situations.

The elevated plus-maze test is based on the creation of a conflict between the exploratory drive of a rat and its innate fear of open, exposed areas. It is one of the most widely used nonconditioned animal models of anxiety and has been extensively validated pharmacologically and ethologically (Dawson and Tricklebank 1995; Pellow 1986; Pich et al. 1993). However, various clinically effective anxiolytic substances often yield contradictory results when administered to "normal" unstressed rats in this test (Griebel 1995; Rodgers et al. 1997), indicating that-in parallel to the situation in humans (Green and Hodges 1991; Lader 1991)—the efficacy of an anxiolytic may depend upon the animal's basal level of anxiety. To test this prediction and to characterize further our breeding lines, in the first experiment, male rats from the $\mathrm{HAB}$ and $\mathrm{LAB}$ lines were injected with a classical anxiolytic, diazepam, and submitted to a plus-maze test and a forced swim test to assess the effects on anxiety-related and stress-coping behavior in the two lines. The forced swim test was initially developed by Porsolt et al. (1977) for the screening of antidepressant drugs. In general, it has been hypothesized that a longer time spent struggling in this inescapable situation reflects an active stress coping strategy; whereas, longer floating (immobility) scores correspond to rather passive coping (Armario et al. 1988; Martí and Armario 1993). In naive rats from the HAB and $L A B$ lines, a correlation between the level of plus-maze anxiety and coping behavior in a forced swim test has been demonstrated, the HAB rats spending more time in an immobile position than the LAB animals that, in contrast to the $\mathrm{HAB}$ rats, change their behavior on the second testing day (Liebsch et al. 1998). We were interested whether an anxiolytic would exert differential effects on anxiety and coping strategy in HAB and LAB rats.

An animal's response to environmental challenges involves physiological, neuroendocrine, and behavioral reactions, all of which are interrelated in a complex manner. A correlation between the type of behavioral stress response; namely, an active coping strategy (of- ten associated with low emotionality) or a passive coping strategy (coupled with high emotionality), and the degree of neuroendocrine reactivity has been demonstrated in many studies (Bohus et al. 1987; Castanon and Mormède 1994; Cools et al. 1993; Gentsch et al. 1988; Walker et al. 1992). Tests of neuroendocrine reactivity have focused predominantly on the hypothalamopituitary-adrenocortical (HPA) axis, the activity of which not only reflects the stress response of the organism, but may also be dysregulated in, for example, socially stressed (subordinate) rats (Blanchard et al. 1995; Mormède et al. 1990) and patients suffering from depression and anxiety disorders (Holsboer et al. 1987; Tyrer 1992). However, some researchers have reported behavioral stress reactions/emotionality to be independent of an activation of the HPA system (Abel 1991; Brush 1991; Courvoisier et al. 1996; Pich et al. 1993). Taking this complex and somewhat confusing background into consideration, this study was designed to characterize the $\mathrm{HAB}$ and $\mathrm{LAB}$ rat lines further with regard to neuroendocrine and physiological parameters that could be associated with (or even be causally linked to) the contrasting behavioral performance of the two lines in tests of anxiety and stress coping. Therefore, to elucidate the context between innate levels of anxiety and physiological changes and reactivity of the HPA system to various stressful events, we implanted rats from both lines with either a small radiotelemetry transmitter or chronic catheters in the jugular vein to be able to monitor body temperature, locomotor activity, food and water intake simultaneously or to draw blood samples from freely moving animals without disturbing them. The rats were submitted either to a 5-min plus-maze test and a 10-min social defeat test (Experiment 2) or to a 5-min plus-maze exposure, a 90 -sec forced swim session, and an intravenous (IV) injection of CRH with plasma ACTH and corticosterone levels being assessed before and at several time points after each stressor (Experiment 3).

\section{METHODS}

\section{Animals}

In 1993, Wistar rats obtained from a commercial supplier (Charles River, Sulzfeld, Germany) were selected using the results from an elevated plus-maze test and mated to establish the lines now termed HAB and LAB (Liebsch et al. 1998). Three pairs per line were used to start the F1 generation. The rats were bred and kept in the animal facility of our institute under controlled laboratory conditions (12-h light-dark cycle with lights on at 6:00 A.M., tap water and standard rat chow ad libitum). At the age of 10 weeks, the offspring from both breeding lines were tested on the elevated plus-maze. For each new generation, two to three $\mathrm{HAB}$ and $\mathrm{LAB}$ 
breeding pairs, respectively, were selected from the rats showing the most anxious (HAB) or nonanxious (LAB) behavior. $\mathrm{HAB}$ animals showing low levels and $\mathrm{LAB}$ rats displaying high levels of anxiety-related behavior, as well as individuals showing no clear tendency toward either of these extremes, were excluded, not only from further breeding, but also from further behavioral testing. Data presented in this paper were obtained from the F5 and F6 generations after crossbreeding with rats from the Leipzig breeding lines selected for high or low performance in an active avoidance task (Hess et al. 1992). This crossing-in was carried out to reinforce anxiety-related behavior in the HAB and LAB lines, because the Leipzig rats also showed differences in freezing behavior indicative of anxiety (Hess et al.). External disturbances and handling were reduced to a minimum.

\section{Experimental Protocols}

Experiment 1: Effects of Diazepam on Anxiety-Related and Stress-Coping Behavior. Eight to nine weeks after their initial plus-maze test, male rats from both lines weighing $506 \pm 10 \mathrm{~g}$ were injected intraperitoneally with either $1 \mathrm{mg} / \mathrm{kg}$ diazepam $\left(V\right.$ alium ${ }^{\circledR}$, injectable solution, Ratiopharm, Ulm, Germany) or vehicle ( $0.9 \%$ saline, containing $13 \%$ ethanol) in an average volume of $0.2 \mathrm{ml}, 30 \mathrm{~min}$ prior to a 5 -min plus-maze test (6 rats per group). On the following 2 days, the respective injections were repeated, and the animals were submitted to a forced swim test ( $15 \mathrm{~min}$ on day 1 and $5 \mathrm{~min}$ on day 2 ) starting $30 \mathrm{~min}$ after the injection.

\section{Experiment 2: Effect of Stress on Body Temperature,} Home Cage Locomotor Activity and Food and Water Intake. Under halothane anaesthesia and sterile conditions, a battery-powered transmitter for continuous radiotelemetric measurement of body temperature and locomotor activity (TA11CTA-F40 Data Sciences International, St. Paul, MN, USA) was implanted into the peritoneal cavity of six male rats from each line, each weighing $483 \pm 10 \mathrm{~g}$, 5 to 6 weeks after their initial plusmaze test. After surgery, the animals were housed individually in plexiglass cages $(25 \times 25 \times 35 \mathrm{~cm})$ placed onto a biotelemetry antenna receiver (Data Sciences International). Food pellets could only be obtained by pressing a lever, which allowed continuous monitoring of food intake, with the water dispensers also being equipped with an electrical contact to monitor licking rate.

A computer-based automatic biotelemetry system (Data Sciences International) was used essentially as described by Schöbitz et al. (1995). Every 2 min, body temperature was measured, and the cumulative locomotor activity score, food-lever pressing, and licking rate for the respective time interval were recorded. Re- cording started on the day of surgery and was continued for the following 12 days. The animals remained undisturbed for 7 days to allow them to recover from surgery and get accustomed to the telemetry cages. Basal parameters were assessed from postsurgery day 4 to day 7, because by then, the diurnal rhythms of all parameters had normalized and were stable. On day 8 , starting at 9:30 A.M., the rats were transferred singly from the telemetry cage to the behavioral laboratory, exposed for $5 \mathrm{~min}$ to the elevated plus-maze, and immediately afterward returned to the telemetry cages. On day 10 at the same time, the individual animals were transferred for $10 \mathrm{~min}$ to the home cage of an aggressive, dominant resident rat couple (social defeat), and then returned to the telemetry cages again.

The 2-min recordings were transformed into weighed mean values over 15-min intervals, from which 6-h means (for the analysis of circadian rhythms) and 45min means (for the analysis of stress effects) were calculated. For baseline (nonstressed) values, group means were calculated from the individual means over days 4 to 7 . For the analysis of stress effects on locomotor activity, 1-h cumulative scores were calculated directly from the 2-min recordings.

Experiment 3: Neuroendocrine Reactivity to Different Stressors. Four to five weeks after their initial plusmaze test, six male rats from each line, weighing $382 \pm$ $12 \mathrm{~g}$, were implanted with chronic jugular vein catheters under halothane anaesthesia 5 days prior to the experiments. The jugular vein was exposed and a silastic tubing catheter (i.d. 0.025 inch, o.d. 0.047 inch, Dow Corning, USA), connected to PE-50 polyethylene tubing, was inserted into the vessel with the tip positioned at the right atrium. The catheter was passed subcutaneously, exteriorized dorsally in the cervical region and plugged by a steel insert. The ventral wound was closed with sterile surgery clips. The catheter was filled with sterile $0.9 \%$ saline containing gentamicin $(30 \mathrm{KIU} / \mathrm{ml}$; Centravet, Germany) and flushed with the same solution 3 days later. Following surgery, rats were housed individually and handled daily to familiarize them with the blood sampling procedure and to minimize nonspecific stress responses during the experiments.

On day 5 after surgery, ACTH and corticosterone secretory responses to a mild emotional stressor were assessed. At 8:00 A.M. the catheters were attached to an extension tubing connected to a 1-ml plastic syringe filled with sterile saline containing heparin $(30 \mathrm{IU} / \mathrm{ml}$, Heparin-Natrium, Ratiopharm, Ulm, Germany), and the rats were then left undisturbed for $90 \mathrm{~min}$. At 9:30 A.M. and 10:00 A.M., 0.2-ml blood samples, substituted immediately by sterile $0.9 \%$ saline, were drawn under basal resting conditions. Then the catheters were disconnected and plugged, and each rat was placed on the elevated plus-maze for $5 \mathrm{~min}$ before being returned to its home 
cage and the catheter being reattached to the syringe. Three more blood samples were taken 5,30 , and $60 \mathrm{~min}$ after return to the home cage. At the end of the experiment, the catheters were flushed with gentamycin solution and plugged.

On day 6, the same blood sampling procedure was repeated, except that rats were exposed to forced swimming (90 s) as an ethologically relevant combined physical and emotional stressor (Abel 1994). The same water tanks as used for the forced swim test were filled up to a level of approximately $50 \mathrm{~cm}$. Struggling, swimming, and floating time were monitored by an experimenter using a PC.

On day 7 after surgery, the procedure was again repeated. This time, instead of exposing them to an exogenous stressor, the rats were injected IV with $40 \mathrm{ng} / \mathrm{kg}$ b.w. rat/human CRH (Ferring, Germany) to assess pituitary reactivity to a defined stimulation with the main corticotropin secretagogue (Antoni 1986; Vale et al. 1981). Blood samples were drawn 10, 30, and 50 min after $\mathrm{CRH}$ infusion.

\section{Behavioral Procedures}

Elevated Plus-Maze. The plus-maze was made of dark gray PVC and consisted of a plus-shaped platform elevated $73 \mathrm{~cm}$ from the floor. Two of the opposing arms $(50 \times 10 \mathrm{~cm})$ were enclosed by $38 \mathrm{~cm}$-high side and end walls (closed arms). The other two arms had no walls (open arms). All four arms were connected at the center by a $10 \times 10 \mathrm{~cm}$ square platform. The maze was lit by two white bulbs above the open arms and two red bulbs above the closed arms (mean light intensity over the whole maze: 100 lux). The apparatus was surrounded by an opaque curtain. The maze was thoroughly cleaned with water containing a detergent before exposing each rat. At the beginning of the test, each animal was placed onto the central area of the maze facing a closed arm. Behavior was monitored for $5 \mathrm{~min}$ by means of a video camera mounted above the platform and scored by a trained observer pressing preset keys on a PC. The following scores were taken: (1) number of entries into open and closed arms (an entry was counted when both forepaws were placed on the respective arm); (2) time spent on each type of arm; (3) latency until the first entry into an open arm; (4) number of full entries (all four paws) into the open arms. Additionally, (5) the total distance traveled on the maze during the testing period was scored by a computerized video-tracking system (Rat + maze III, V 1.3; Bures, Krekule, Kaminsky, University of Prague, Czech Republic).

For the selection of the breeding pairs, all parameters scored were taken into account, with particular emphasis on the percentage of time spent on the open arms (relative to the time on all arms) as the main indicator of anxiety. The other parameters were used in the following rank order: percentage of entries into the open arms $>$ number of full open-arm entries $>$ latency to first openarm entry. Only animals with average activity scores (distance traveled) were selected.

Forced Swim Test. In Experiment 1, rats from both lines that had been tested on the plus-maze 1 day before were subjected to the forced-swim procedure adapted from Porsolt et al. (1977). On the 1st day of the test, each rat was forced to swim for $15 \mathrm{~min}$ in a cylindrical plexiglass tank (50-cm high and 30-cm diameter), filled with water $\left(19^{\circ} \mathrm{C}\right)$ up to a level of $25 \mathrm{~cm}$. On the 2 nd day, 24 hours later, the rat was re-exposed to the tank for $5 \mathrm{~min}$. After each swimming session, the rat was gently dried with a towel and returned to its home cage, which was placed under a heating lamp until the rat's fur was completely dry. The water in the tanks was changed for each rat. The animal's behavior during the (first) $5 \mathrm{~min}$ of the swim test was scored by a trained observer pressing preset keys on a PC. The following measures were taken: (1) time spent struggling, defined as strongly moving all four limbs with the front paws breaking the water surface or scratching the tank wall; (2) time spent swimming, defined as moving all four limbs, swimming around in the tank or diving; (3) time spent floating, defined as remaining immobile with only occasional slight movements to keep the body balanced and the nose above water; and (4) latency until the first floating reaction. In Experiment 3, rats were forced to swim for $90 \mathrm{~s}$ in the tanks filled with water up to $50 \mathrm{~cm}$.

Social Defeat. Social defeat was used as a (predominantly emotional) stressor and anxiogenic stimulus. The procedure adapted with modifications from Miczek (1979) consisted of placing the rat into the home cage of a dominant male resident (and its female) that had been trained to be aggressive toward intruders. The intruder was attacked and subdued by the resident within the 1st minute of the encounter and continuously threatened and/or attacked during the following $10 \mathrm{~min}$ while it displayed submissive or defensive body postures. Defeat was considered successful if the intruder had been attacked and subdued at least once and had spent at least $6 \mathrm{~min}$ in a submissive/defensive body posture (e.g., lying on the back or defensive upright posture) or freezing.

\section{Hormone Assays}

All blood samples were collected in EDTA-coated tubes containing aprotinin (Trasylol ${ }^{\circledR}$, Bayer, Leverkusen, Germany) on ice and centrifuged at $4^{\circ} \mathrm{C}(4,000 \mathrm{rpm}, 5$ $\mathrm{min}) .80 \mu \mathrm{l}$ (for ACTH assay) and $30 \mu \mathrm{l}$ (for corticosterone assay) plasma aliquots were stored at $-80^{\circ} \mathrm{C}$ and $-20^{\circ} \mathrm{C}$, respectively. Plasma ACTH and corticosterone levels were measured using commercially available radioimmunoassay kits (ACTH: Biochem Immunosystems, 
Germany, sensitivity $<1.0 \mathrm{pg} / \mathrm{ml}$; Corticosterone: DRGInstruments, Germany, sensitivity $<2.0 \mathrm{ng} / \mathrm{ml}$ ) according to the respective protocols. The intra- and interassay coefficients of variation were 7 and $10 \%$, respectively.

\section{Statistics}

Statistical analysis was performed using statistical software (GB-stat V6.0; Dynamic Microsystems, USA). Analysis of the behavioral parameters obtained in Experiment 1 was carried out using a two-way analysis of variance (ANOVA) (line $\times$ treatment; plus-maze test) or a three-way ANOVA) (line $\times$ treatment $\times$ time) with repeated measures on the last factor (forced-swim test).

For the analysis of body temperature, locomotor activity, food and water intake, and their respective circadian rhythms (Experiment 2), data from 9 days of continuous biotelemetric recording were transformed into 6-h mean values and subjected to two-way ANOVAs (line $\times$ time) for repeated measures. For the analysis of body temperature changes in response to stress, $45-\mathrm{min}$ mean values were calculated and subjected to a threeway ANOVA (line $\times$ stress $\times$ time) with repeated measures on the last two factors. Locomotor activity after stress exposure was analysed from 1-h cumulative scores subjected to a two-way ANOVA for repeated measures.

Plasma ACTH and corticosterone levels (Experiment 3) were compared using a two-way ANOVA for repeated measures (line $\times$ time intervals). For comparison of total amount of hormone release, the area under the curve (AUC) was calculated using trapezoidal integration. Additionally, delta values (maximum poststress minus baseline levels) were calculated. AUC and delta values for each stress condition were compared using the Mann-Whitney U-test. Where appropriate, the ANOVAs were followed by Fisher's LSD protected $t$-test. Probability $(p<.05)$ was considered statistically significant. Data are presented as group means \pm SEM, if not indicated otherwise.

\section{RESULTS}

\section{Experiment 1}

Elevated Plus-Maze. A two-way ANOVA (line $\times$ treatment) on the main plus-maze parameters confirmed that $\mathrm{HAB}$ rats displayed a lower percentage of entries into $\left(\mathrm{F}_{1,20}=51.99, p<.001\right)$ and time spent on $\left(\mathrm{F}_{1,20}=\right.$ $72.35, p<.001)$ the open arms of the plus-maze than the animals from the LAB line. Accordingly, the latency until the first open-arm entry was much higher $\left(\mathrm{F}_{1,20}=\right.$ 55.97, $p<.001)$ and the number of full entries into the open arms much smaller $\left(\mathrm{F}_{1,20}=40.83, p<.001\right)$ in HAB than in LAB rats. In both lines, injection with $1 \mathrm{mg} / \mathrm{kg}$ diazepam resulted in an increase in open-arm explora- tion compared to vehicle-treated controls from the respective line ( $\%$ entries; $\mathrm{F}_{1,20}=27.36, p<.001 ; \%$ time: $\mathrm{F}_{1,20}=31.19, p<.001$; latency: $\mathrm{F}_{1,20}=53.31, p<.001$; full entries: $F_{1,20}=13.33, p=.002$ ), but there was also a significant interaction between the factors line and treatment for all parameters ( $\%$ entries: $\mathrm{F}_{1,23}=10.50, p=$ .004 ; \% time: $\mathrm{F}_{1,23}=8.20, p=.009$; latency: $\mathrm{F}_{1,23}=39.31$, $p<.001$; full entries: $\mathrm{F}_{1,23}=7.5, p=.013$ ), indicating differential anxiolytic efficacy in the two lines. Post-hoc analysis showed that the percentage of open-arm entries in diazepam-treated HAB rats was no longer different from the LAB animals, and the percentage of time spent on these arms equalled the vehicle-treated $\mathrm{LAB}$ rats (Figure 1). In fact, diazepam injection resulted in a 20-fold increase in percentage time spent on the open arms in the HAB animals, as compared to a 2.5fold increase in the LAB rats. Correspondingly, the latency until the first open-arm entry decreased 7-fold in diazepam-treated HAB rats and only 2-fold in the LAB animals, and the increase in the percentage of open-arm entries was 5.6-fold in the HAB rats versus 1.2-fold in $\mathrm{LAB}$ animals. The total distance traveled during the 5-min test was not significantly different between the groups $(p=.095)$, indicating that the rats did not differ in their general locomotor activity on the maze.

Forced Swim Test. A three-way ANOVA (line $\times$ treatment $\times$ time) with repeated measures on the last factor revealed a significant line difference in all parameters measured except swimming time (time spent struggling: $\mathrm{F}_{1,20}=37.01, p<.001$; floating: $\mathrm{F}_{1,20}=17.34, p<$ .001 ; latency to first floating: $\mathrm{F}_{1,20}=11.70, p=.003$ ). Change over time was detected in all parameters (time spent struggling: $\mathrm{F}_{1,20}=22.62, p<.001$; swimming: $\mathrm{F}_{1,20}=$ 6.70, $p=.018$; floating: $\mathrm{F}_{1,20}=21.56, p<.001$; latency to first floating: $\left.\mathrm{F}_{1,20}=18.68, p<.001\right)$, with a significant interaction with factor line (struggling: $\mathrm{F}_{1,20}=21.01, p<$ .001 ; floating: $F_{1,20}=12.93, p=.002$; latency to first floating: $\mathrm{F}_{1,20}=6.85, p=.016$ ) and with factor treatment (struggling: $\mathrm{F}_{1,20}=20.04, p<.001$; swimming: $\mathrm{F}_{1,20}=$ $6.12, p=.022)$. Nevertheless, a significant treatment effect was found only in the latency to the first floating reaction $\left(\mathrm{F}_{1,20}=12.23, p=.002\right)$, and for the time spent struggling, an interaction between factors line and treatment was detected $\left(\mathrm{F}_{1,24}=6.36, p=.020\right)$. Significant differences in each particular parameter as revealed by post-hoc comparison are indicated in Figure 2. Independent of drug treatment, $\mathrm{HAB}$ rats struggled less and floated more than $L A B$ animals on the first testing day $(p<.01)$. On the second day, the LAB rats changed their behavior to a pattern similar to that displayed by the $\mathrm{HAB}$ animals on both days. Compared to vehicle treatment, diazepam had no effect on the behavior of the $\mathrm{HAB}$ rats on the first day; whereas, it increased struggling time but decreased latency to floating on the second day $(p<.01)$. In contrast, diazepam-treated LAB 

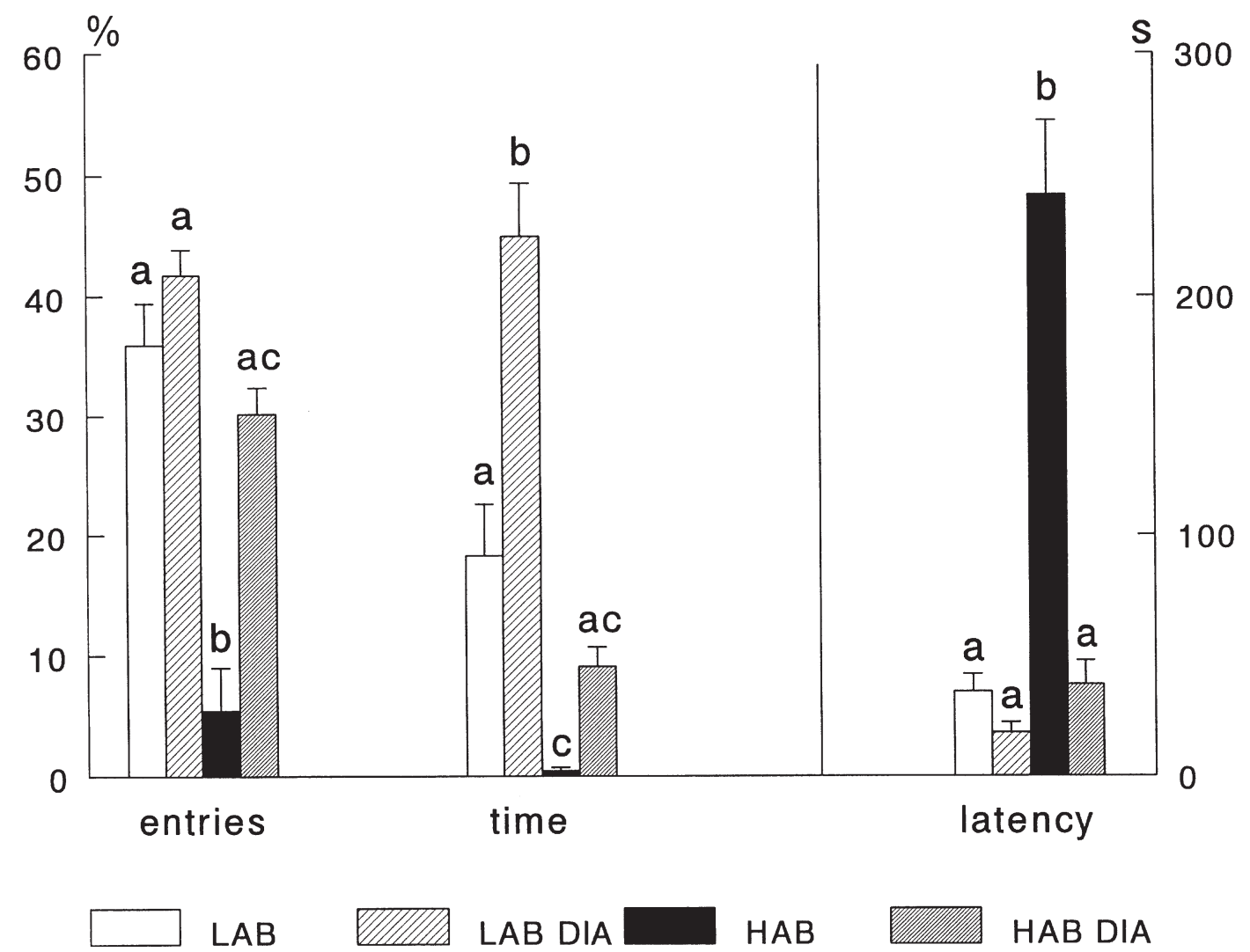

Figure 1. Behavioral parameters (means + SEM) of HAB and LAB rats in the elevated plus-maze test 30 min after intraperitoneal injection of $1 \mathrm{mg} / \mathrm{kg}$ diazepam (DIA) or vehicle ( $n=6$ per group). Percentage of entries into and time spent on the open arms to over-all arm entries and time, respectively, as well as the latency until the first open-arm entry are given as indicators of anxiety-related behavior. Within each parameter, groups labeled with different letters differ significantly $(p<$ .01; Fisher's LSD test).

rats struggled less and started floating earlier than their vehicle-treated controls on the first day of the test $(p<$ .01) but were unaffected on the second day (Figure 2).

\section{Experiment 2}

Because of abnormally low body temperature, weight loss, and signs of sickness behavior, one LAB animal was excluded from the statistical analysis.

Body Temperature. No differences between HAB and $\mathrm{LAB}$ rats were found in body temperature on the baseline days preceding the stress tests or on the days following the stress tests, as shown in Figure 3A. Except for the lower starting temperature in the HAB rats on day 4 , baseline day and night peak values, trough values and delta-to-peak values (assessed from 30-min means) also showed no differences between the lines. A significant line $\times$ time interaction $\left(\mathrm{F}_{8,98}=2.31, p=.029\right)$ was detected for the amplitudes of the circadian rhythm (nighttime peak minus daytime trough). Mainly attributable to an increase in daytime body temperature, this amplitude was significantly reduced, as compared to baseline and poststress values in both lines on the day of social defeat stress $(p<.01)$ but after plus-maze exposure, the decrease reached significance only in the HAB rats $(p<.05)$. Interestingly, the temperature amplitudes did not differ between the baseline days, day 9 (between stress exposures), and the 2 poststress days in either line, indicating that there was no long-term effect of the two stressors on the diurnal rhythm in body temperature.

Analysis of four consecutive 45-min mean values following stress exposure compared to baseline values of the respective time of day (group means over days 4-7) revealed no significant line effect $(p=.35)$, but a significant influence of factor stress $\left(\mathrm{F}_{2,18}=35.62, p<.001\right)$ and factor time $\left(\mathrm{F}_{3,27}=13.55, p<.001\right)$, as well as an interaction between all three factors $\left(\mathrm{F}_{6,131}=2.86, p=\right.$ .017). Results of the post-hoc analysis are indicated in Figure 4. During all four time intervals, poststress scores were significantly higher than the baseline values, which did not differ between the lines. Therefore, Figure 4 shows the temperature increases from the respective baseline means. Following a 5-min exposure to the elevated plus-maze, the body temperature of LAB 

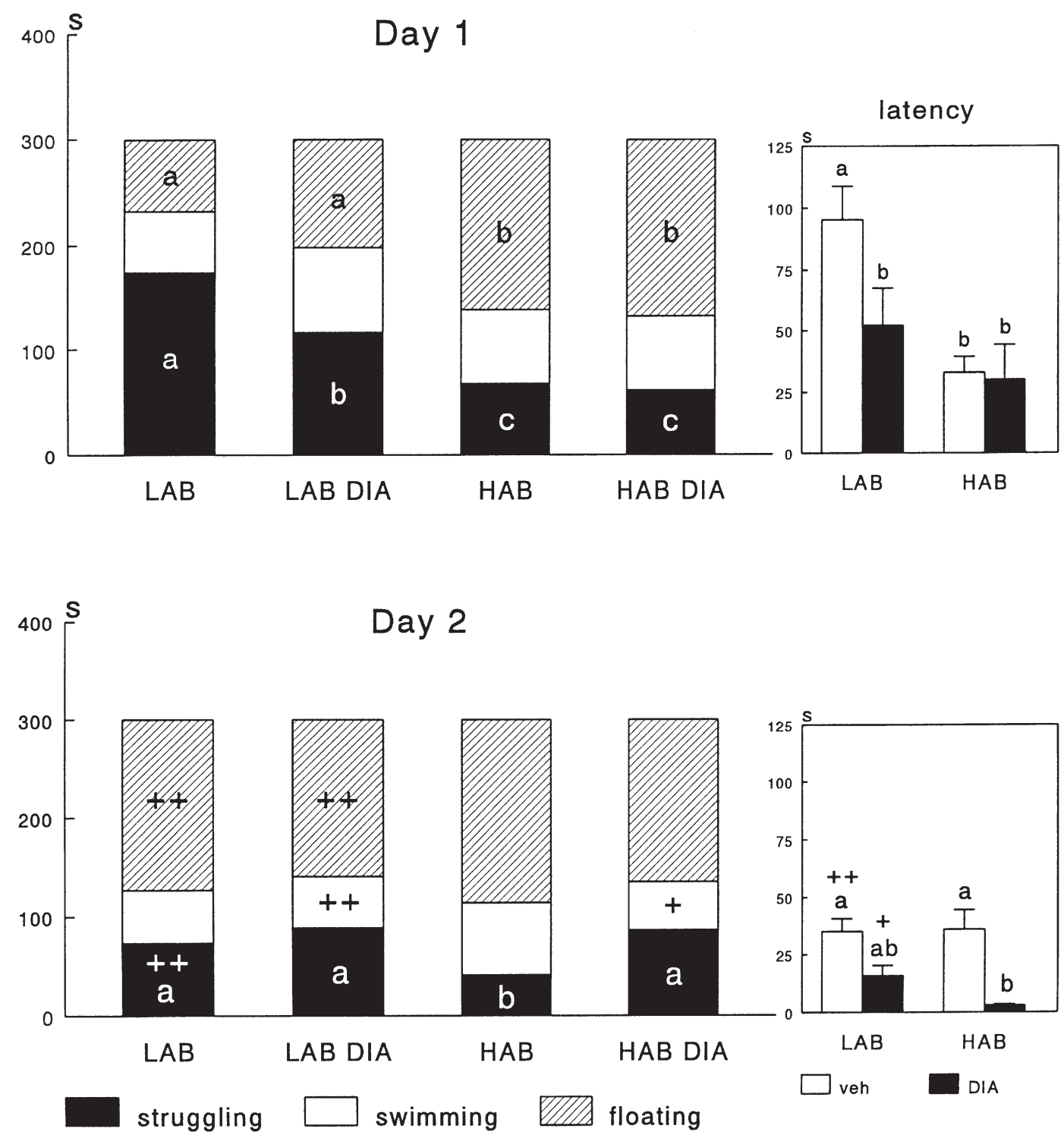

Figure 2. Behavioral parameters of $\mathrm{HAB}$ and $\mathrm{LAB}$ rats in the forced-swim test 30 min after intraperitoneal injection of $1 \mathrm{mg} / \mathrm{kg}$ diazepam (DIA) or vehicle ( $n=6$ per group). Time (means) spent struggling, swimming, and floating during the (first) $5 \mathrm{~min}$ of both testing days. The latency until the first floating reaction (mean + SEM) for each day is depicted in the right-hand panels. Within each parameter and day, groups labeled with different letters differ significantly $(p<.05 ;$ Fisher's LSD test). $+p<.05$ and $++p<.01$ vs. the same parameter on day 1 .

rats showed a significantly greater increase than that of $\mathrm{HAB}$ rats during the first $45 \mathrm{~min}$ after return to the home cage $(p<.01)$. However, this difference was reversed during the following two 45-min intervals $(p<$ $.05)$ as the temperature of the LAB rats decreased rapidly; whereas, it stayed elevated in the HAB rats. During the first 45-min interval after a 10-min social defeat experience, body temperature rose significantly higher than after plus-maze exposure in both lines $(p<.05)$. Again, the increase was much more pronounced in the LAB animals $(p<.01)$, but the reversal effect during the following time intervals failed to reach statistical significance.
Locomotor Activity. Although the LAB rats seemed to be more active, especially during the night, no significant line difference in activity was detected on the days after stress exposure, as shown in Figure 3B. When the 4 days preceding the stress tests were analyzed separately, no significant line effect was found either $(p=$ .059), but an interaction between factors line and time $\left(\mathrm{F}_{15,175}=1.89, p=.029\right)$ was. This was attributed to the higher activity of the $\mathrm{LAB}$ rats solely during the nights of days 4 and 6 (Figure 3B). However, no differences between $\mathrm{HAB}$ and $\mathrm{LAB}$ rats were found in the amplitudes of the circadian rhythm (nighttime maximum minus daytime minimum), although plus-maze exposure and 

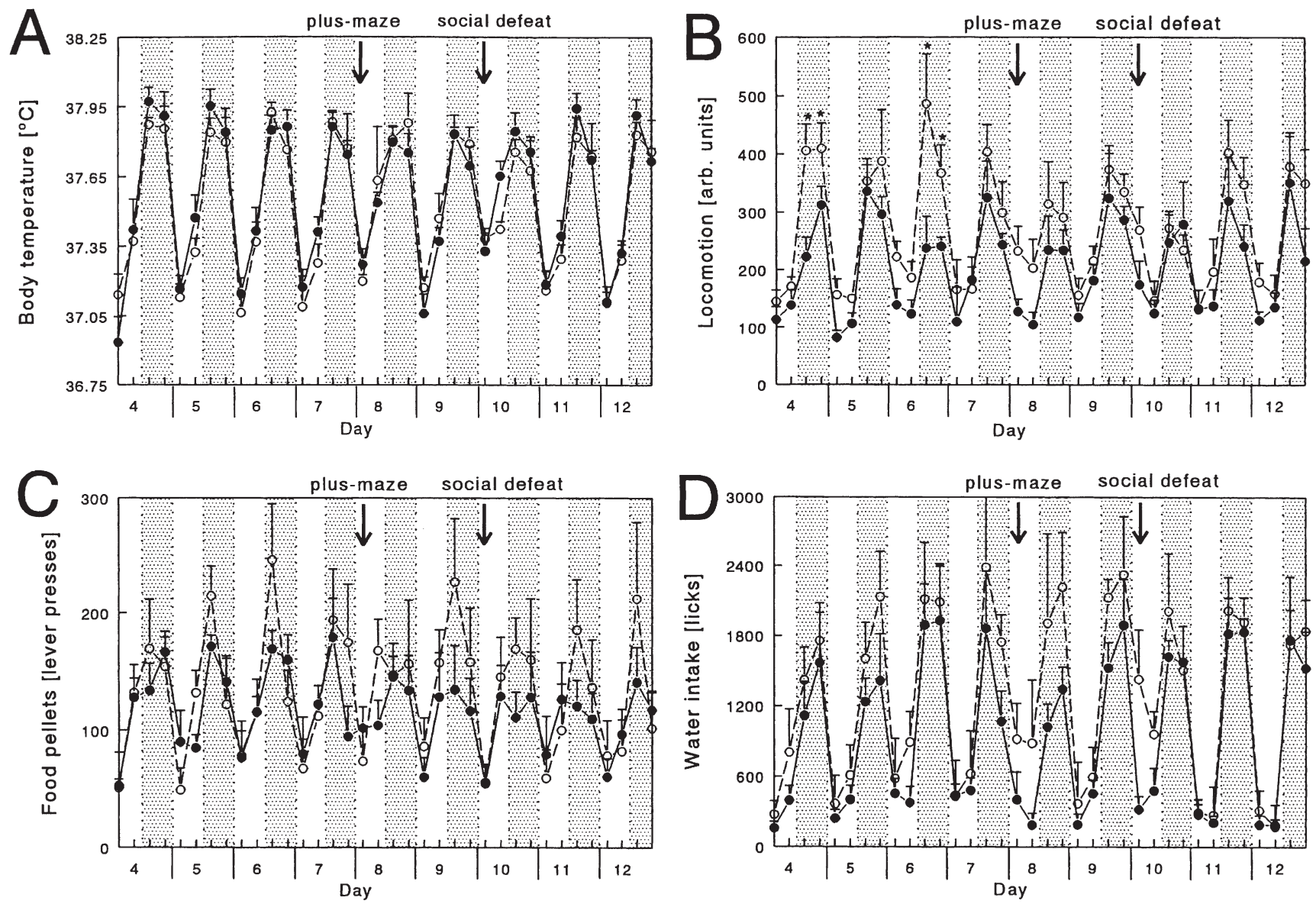

Figure 3. Circadian rhythms of body temperature (A), locomotor activity (B), food intake (C), and water intake (D) of male HAB (filled circles; $n=6$ ) and LAB (open circles; $n=5$ ) rats over 9 days of continuous biotelemetrical recording, starting on day 4 after surgery. Data represent means + SEM over $6 \mathrm{~h}$. Each day is divided into four 6-h periods, with periods 1 and 2 denoting the light phase (unshaded areas) and periods 3 and 4 denoting the dark phase of the light/dark cycle (shaded areas). The time points of stress exposure are indicated by arrows. Panel B: ${ }^{* *} p<.01$ and ${ }^{*} p<.05$ vs. HAB (Fisher's LSD test) when days 4 to 7 are assessed separately (for details see Results section).

social defeat evidently reduced subsequent nighttime activity in both lines (Figure 3B). Acute changes in locomotor activity following stress exposure were analyzed from 1-h cumulative scores (Figure 5). In contrast to the line difference in body temperature change, LAB rats displayed higher activity scores than $\mathrm{HAB}$ animals during the first $4 \mathrm{~h}$ after plus-maze exposure $\left(\mathrm{F}_{1,9}=5.14\right.$, $p=.049$ (factor line); $\mathrm{F}_{3,43}=0.72, p=.55$ (line $\times$ time)), and a trend toward higher activity was still evident until $10 \mathrm{~h}$ after this mild stress $(p=.055$; Figure 5A). Social defeat strongly increased locomotion in the LAB, but not the HAB rats $\left(\mathrm{F}_{1,9}=9.87, p=.012\right.$ [factor line]; $\mathrm{F}_{3,43}=$ $10.55, p<.001$ [line $\times$ time]), but only within the first hour after return to the home cage $(p<.01$; Figure 5B).

Food Intake. As depicted in Figure 3C, rats from the $\mathrm{HAB}$ and $\mathrm{LAB}$ line did not show significant differences in lever pressing for food pellets either on the baseline days preceding the stress tests, on the days of stress ex- posure, or on the days following the stress tests, although stress exposure seemed to depress eating during the night in the HAB rats (Figure $3 \mathrm{C}$ ). Correspondingly, body weight gain over the whole experimental period was slightly but not significantly lower in HAB than in LAB rats ( $p=.079$, data not shown).

Water Intake. No line difference was found in the number of licks on the water dispensers on the baseline days preceding the stress tests or on the days following the stress tests. On the day of plus-maze exposure (day 8), there was a trend toward a line difference $\left(\mathrm{F}_{1,9}=4.71, p=\right.$ .058), with an increased licking rate in the LAB rats during the light period and a decreased licking activity in the HAB rats during the dark period. On the day of social defeat stress (day 10), a trend toward an interaction between factors line and time $\left(\mathrm{F}_{3,27}=2.63, p=.071\right)$ indicated increased licking in the LAB rats, but only during the light period (Figure 3D). 

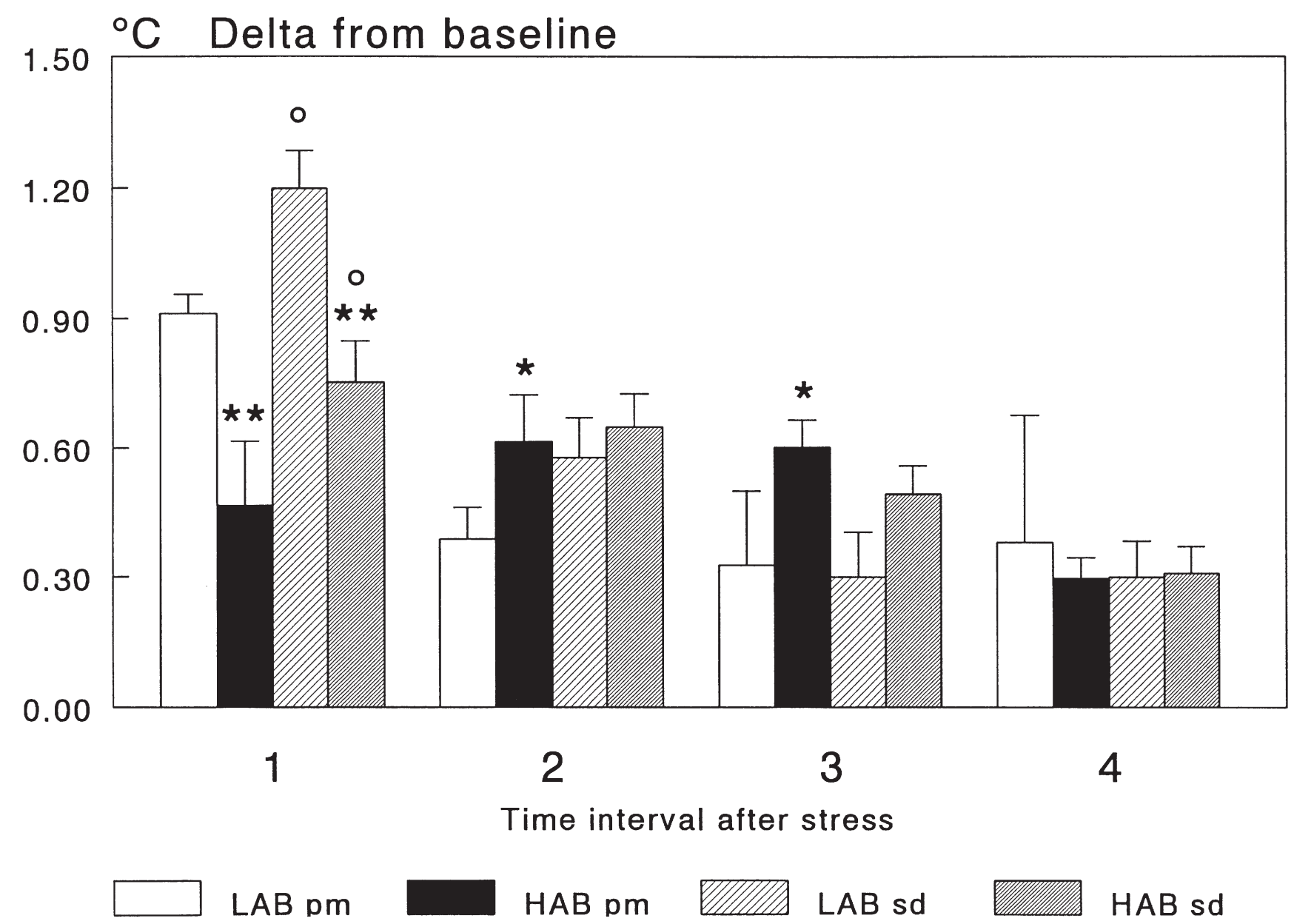

Figure 4. Changes in body temperature of male $\operatorname{HAB}(n=6)$ and $\operatorname{LAB}(n=5)$ rats during four consecutive 45-min intervals after exposure to the elevated plus-maze (pm; filled bars) or to a social defeat paradigm (sd; hatched bars). For each time interval, the respective group means from the previous, stress-free days (baseline values) were subtracted from the absolute values. ${ }^{* *} p<.01$ and ${ }^{*} p<.05$ vs. LAB under the same stress condition; $\bigcirc p<.05$ vs. plus-maze stress in the same line (Fisher's LSD test).

\section{Experiment 3}

Basal A.M. plasma levels of ACTH and corticosterone were not different between the $\mathrm{HAB}$ and $\mathrm{LAB}$ line on all 3 experimental days. All three stressors (plus-maze, forced swimming, $\mathrm{CRH}$ injection) induced a significant increase in both ACTH and corticosterone concentrations $(p<.001$; Table 1$)$. However, no significant line differences were detected under either of the stress conditions for ACTH and corticosterone levels. AUC and delta-to-peak values for ACTH and corticosterone were also not significantly different between the lines on all three days (Table 1). It was only on the day of plusmaze exposure that a trend-interaction between factors line and time $\left(\mathrm{F}_{4,59}=2.27, p=.078\right)$ indicated that the $\mathrm{HAB}$ rats tended toward an increased $\mathrm{ACTH}$ secretion in response to this mild, predominantly emotional stressor (Figure 6). It seems noteworthy, however, that there was one individual showing almost no increase in $\mathrm{ACTH}$ in response to plus-maze exposure ("nonre- sponder") in each group. When these two individuals were excluded from the analysis, the line-time interaction became significant $\left(\mathrm{F}_{4,49}=3.04, p=.031\right)$, and the increase in ACTH secretion 5 min after plus-maze stress was significantly higher in HAB rats than in LAB animals $(p<.05)$. Although-corresponding to their first test at the age of 10 weeks - there was a marked difference in the behavioral performance on the plus-maze, with the HAB rats making fewer entries into $(p<.05)$ and spending less time $(p<.01)$ on the open arms of the maze than the LAB rats (data not shown), no significant correlation between ACTH increase (delta-to-peak) and percentage of time spent on the open arms was detected.

On the second experimental day (forced swimming), despite the fact that $\mathrm{HAB}$ rats spent less time struggling $(p<.05)$ and tended to spend more time floating ( $p=$ .07) than the LAB animals (data not shown), the amount of ACTH and corticosterone secretion was similar in 

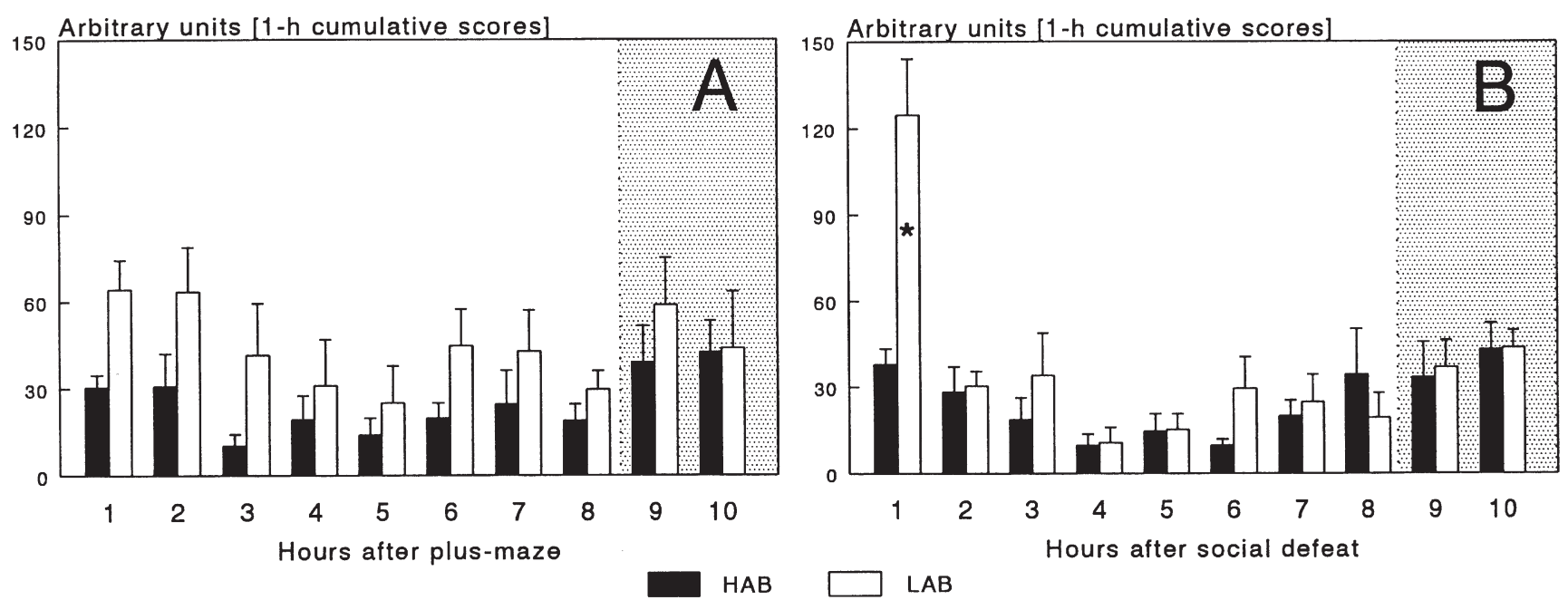

Figure 5. Locomotor activity (1-h cumulative scores) of male HAB $(n=6)$ and LAB $(n=5)$ rats following exposure to the elevated plus-maze (panel A) or to a social defeat paradigm (panel B). The shaded areas indicate the dark periods of the light/dark-cycle. ${ }^{*} p<.01$ vs. HAB and all other time points (Fisher's LSD test).

both groups (Table 1), indicating that the experience of stress was independent of the behavioral performance in this situation.

Despite the lack of significant differences in ACTH and corticosterone levels following IV CRH injection on experimental day 3 in both groups, indicating a similar reactivity of the anterior pituitary corticotrope cells in the two lines, this was the only condition where $\mathrm{HAB}$ rats tended toward lower ACTH and corticosterone levels than LAB rats (Table 1).

\section{DISCUSSION}

The $\mathrm{HAB}$ and $\mathrm{LAB}$ rat lines, differing markedly in their inborn anxiety-related and stress-coping behavior (Liebsch et al. 1998), may provide a promising tool for investigating the relationship between anxiety, stress coping, physiological, and neuroendocrine stress responses, and their underlying mechanisms. This study was designed to characterize further the HAB and LAB lines concerning their susceptibility to anxiolytic treatment and alterations in physiological and neuroendocrine parameters in response to environmental challenges.

The results demonstrate that, although an anxiolytic effect of diazepam was evident in both lines, the HAB rats were more sensitive to the anxiolytic effect, because diazepam treatment increased their open-arm exploration in the plus-maze to a much greater extent than that of the LAB rats. This kind of differential reactivity to diazepam has also been observed by others in inbred rat strains differing in anxiety-related behavior (Commissaris et al. 1990; Ramos et al. 1997). Although further experiments are needed to examine the differential reac- tivity to anxiolytics in the $\mathrm{HAB}$ and $\mathrm{LAB}$ rats in more detail (for example, by determining the anxiolytic threshold dose in both lines) the present findings support the notion that the efficacy of pharmacological manipulation of anxiety-related behavior depends upon the basal level of anxiety (Fernandez-Teruel et al. 1991; Gendron and Brush 1996; Ramos et al. 1997; Rodgers et al. 1997) and may provide an explanation for the frequent failures of clinically effective anxiolytics when screening tests are performed on normal animals (Handley et al. 1993; Rodgers et al. 1997; Stephens and Andrews 1991). Differences in central benzodiazepine/ GABA-A receptors, through which diazepam exerts its action, have been demonstrated in anxious and nonanxious rats and mice (Chapouthier et al. 1991; Clément et al. 1997; Robertson et al. 1978). Interestingly, even under the influence of diazepam at the dose of $1 \mathrm{mg} / \mathrm{kg}$, $\mathrm{HAB}$ rats did not spend as much time exploring the open arms as vehicle-treated LAB rats (Figure 1). This underlines the extreme difference between the two lines and provides further validation of the $\mathrm{HAB}$ and $\mathrm{LAB}$ lines as a model for studying the mechanisms underlying the regulation of anxiety-related behavior.

The high versus low levels of emotionality in the $\mathrm{HAB}$ and LAB rats, respectively, have been demonstrated to correlate with passive versus active coping behavior in a forced-swim test (Liebsch et al. 1998), in agreement with the performance of other rat lines and strains differing in emotionality (Abel 1991; Armario et al. 1995; Bohus et al. 1987; Lahmame et al. 1997; Overstreet et al. 1992; Paré 1992; Steimer et al. 1997) and in line with the concept of the "searching-waiting strategy" proposed by Thierry et al. (1984). On the other hand, there are reports on other strains and lines where 
Table 1. Plasma ACTH and Corticosterone (Cort) Concentrations in Response to Different Stressors in Male HAB and LAB Rats ( $n=6$ per group)

\begin{tabular}{|c|c|c|c|c|c|c|c|}
\hline \multicolumn{8}{|c|}{ Plus-Maze } \\
\hline Line & Basal 1 & Basal 2 & 5 Min & $30 \mathrm{Min}$ & $60 \mathrm{Min}$ & Delta to Peak & AUC [Units] \\
\hline \multicolumn{8}{|l|}{ HAB } \\
\hline ACTH $[p g / m l]$ & $18.7 \pm 7.9$ & $9.12 \pm 2.8$ & $342 \pm 92$ & $215 \pm 62$ & $56.1 \pm 16$ & $333 \pm 90$ & $132 \pm 35$ \\
\hline Cort $[\mathrm{ng} / \mathrm{ml}]$ & $79.4 \pm 37$ & $31.3 \pm 11$ & $227 \pm 32$ & $271 \pm 62$ & $185 \pm 49$ & $196 \pm 25$ & $160 \pm 35$ \\
\hline \multicolumn{8}{|l|}{$\mathrm{LAB}$} \\
\hline $\mathrm{ACTH}[\mathrm{pg} / \mathrm{ml}]$ & $13.6 \pm 6.4$ & $25.7 \pm 21$ & $171 \pm 34$ & $159 \pm 57$ & $69.2 \pm 37$ & $145 \pm 39$ & $91.1 \pm 24$ \\
\hline Cort $[\mathrm{ng} / \mathrm{ml}]$ & $54.5 \pm 17$ & $48.8 \pm 24$ & $237 \pm 41$ & $219 \pm 61$ & $184 \pm 82$ & $188 \pm 45$ & $147 \pm 36$ \\
\hline \multicolumn{8}{|c|}{ Forced Swimming } \\
\hline Line & Basal 1 & Basal 2 & 5 Min & 30 Min & 60 Min & Delta to Peak & AUC [Units] \\
\hline \multicolumn{8}{|l|}{ НАB } \\
\hline $\mathrm{ACTH}[\mathrm{pg} / \mathrm{ml}]$ & $39.6 \pm 32$ & $6.13 \pm 2.5$ & $317 \pm 47$ & $102 \pm 12$ & $31.2 \pm 9.6$ & $311 \pm 47$ & $90.5 \pm 9.6$ \\
\hline Cort $[\mathrm{ng} / \mathrm{ml}]$ & $57.0 \pm 37$ & $48.1 \pm 20$ & $195 \pm 38$ & $310 \pm 60$ & $98.8 \pm 23$ & $147 \pm 40$ & $149 \pm 24$ \\
\hline \multicolumn{8}{|l|}{$\mathrm{LAB}$} \\
\hline ACTH $[p g / m l]$ & $18.4 \pm 13$ & $9.78 \pm 2.7$ & $255 \pm 16$ & $92.7 \pm 11$ & $31.1 \pm 4.6$ & $246 \pm 17$ & $75.6 \pm 3.2$ \\
\hline Cort $[\mathrm{ng} / \mathrm{ml}]$ & $49.1 \pm 25$ & $24.5 \pm 10$ & $176 \pm 51$ & $272 \pm 81$ & $92.9 \pm 25$ & $151 \pm 44$ & $129 \pm 35$ \\
\hline \multicolumn{8}{|c|}{ CRH Stimulation } \\
\hline Line & Basal 1 & Basal 2 & 10 Min & 30 Min & $50 \mathrm{Min}$ & Delta to Peak & AUC [Units] \\
\hline \multicolumn{8}{|l|}{ НАB } \\
\hline $\mathrm{ACTH}[\mathrm{pg} / \mathrm{ml}]$ & $7.06 \pm 1.6$ & $11.2 \pm 6.1$ & $123 \pm 34$ & $59.8 \pm 16$ & $26.6 \pm 6.1$ & $112 \pm 34$ & $36.4 \pm 8.9$ \\
\hline Cort $[\mathrm{ng} / \mathrm{ml}]$ & $24.4 \pm 8.0$ & $57.1 \pm 33$ & $153 \pm 32$ & $188 \pm 31$ & $104 \pm 26$ & $95.5 \pm 30$ & $85.9 \pm 17$ \\
\hline \multicolumn{8}{|l|}{ LAB } \\
\hline ACTH $[p g / m l]$ & $5.91 \pm 1.4$ & $4.62 \pm 1.1$ & $135 \pm 21$ & $80.9 \pm 14$ & $28.6 \pm 6.6$ & $131 \pm 22$ & $41.2 \pm 5.8$ \\
\hline Cort $[\mathrm{ng} / \mathrm{ml}]$ & $26.1 \pm 12$ & $13.1 \pm 5.2$ & $160 \pm 32$ & $208 \pm 38$ & $124 \pm 25$ & $147 \pm 31$ & $84.5 \pm 16$ \\
\hline
\end{tabular}

this kind of correlation has not been found (Viglinskaya et al. 1995; Zhukov and Vinogradova 1994), and we should always keep in mind that in some strains and lines, there is even a lack of correlation between the behavioral performance in different tests of emotionality (Chaouloff et al. 1994; Overstreet et al. 1996; Ramos et al. 1997; Zhukov and Vinogradova 1994). In the present experiment, the same differential behavioral patterns in the forced-swim test as seen in our previous study (Liebsch et al. 1998) were observed in HAB and $\mathrm{LAB}$ rats regardless of drug treatment; namely, higher immobility scores, less struggling, and a shorter latency to floating in HAB rats (Figure 2). The only effect of diazepam on $L A B$ rats was a reduction of struggling time and latency to first floating on the first day of the swim test, as compared to vehicle controls, possibly reflecting a slightly relaxing, if not sedative, effect of diazepam. Nevertheless, even in diazepam-treated LAB rats, struggling time was still longer and floating time shorter than in HAB rats that were completely unaffected by diazepam during the first exposure. Again consistent with previous findings in naive $\mathrm{LAB}$ rats (Liebsch et al.), animals from this line changed their behavior to a more passive pattern on day 2; that is to one similar to that of the HAB rats on both days (Figure 2). The increase in struggling time in diazepam-treated $\mathrm{HAB}$ rats on the second day of the test as compared to vehicle controls is the only effect that could be interpreted as counteracting passive behavior. It has to be emphasized, however, that the time spent floating (immobility), which is taken as the main indicator of coping behavior in most studies, was completely unaffected by diazepam treatment in either group on both days, a result that is in good agreement with previous findings (Martí and Armario 1993; Porsolt et al. 1977). Thus, at the same dosage that induced a clear anxiolytic effect in the elevated plus-maze test in the HAB and LAB rats, diazepam did not affect the overall pattern of coping behavior in the forced-swim test, suggesting either that the dosage was not high enough to overcome the certainly stronger stressor of forced swimming, or that plus-maze anxiety and coping strategy in the forcedswim test are regulated independently by means of different mechanisms. Evidence for the latter hypothesis also comes from findings in the Roman rat lines (Steimer et al. 1997).

Another finding for the characterization of our breeding lines that might, in part, indicate a possible contri- 


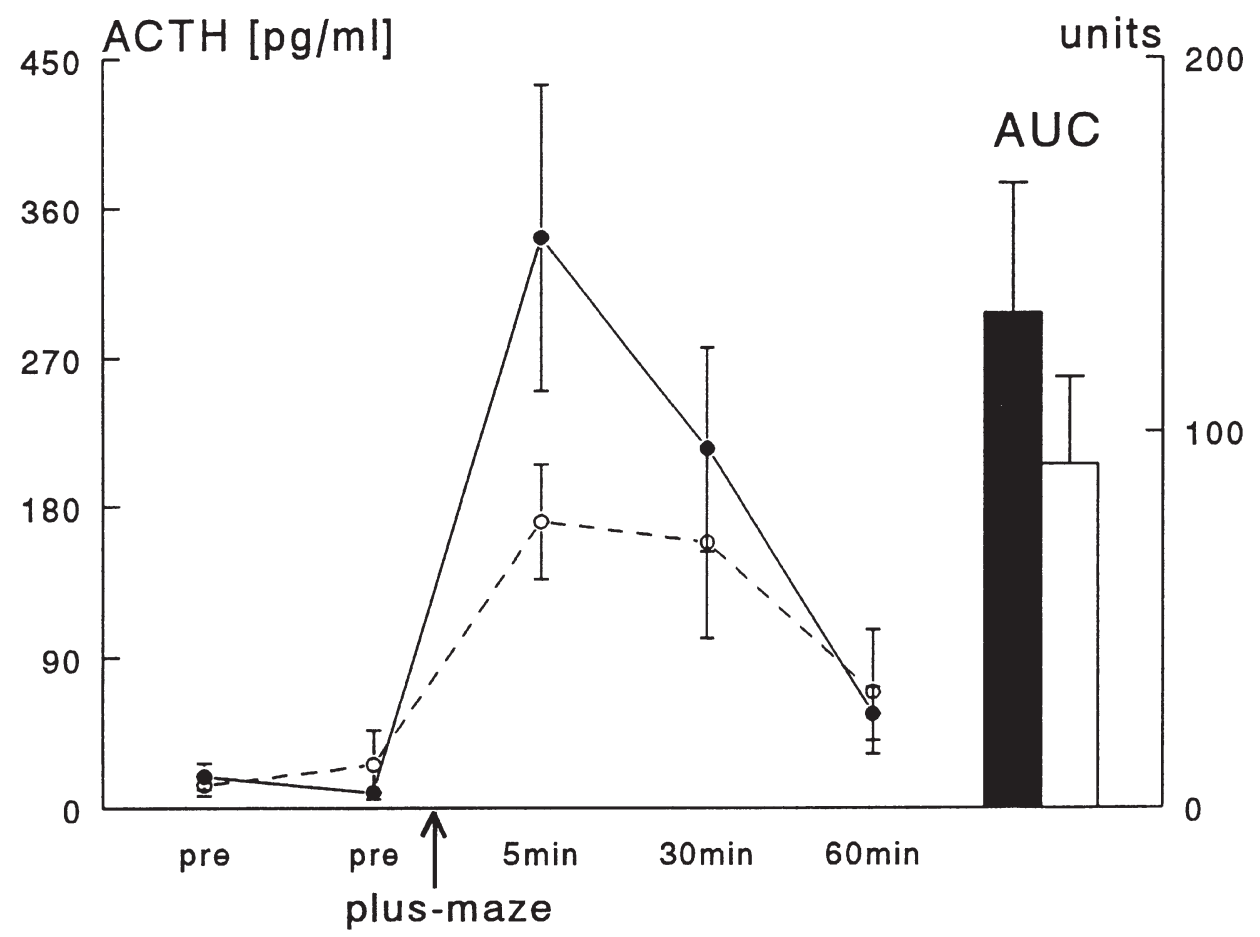

$\square$ HAB $\square L A B \quad--H A B-0-L A B$

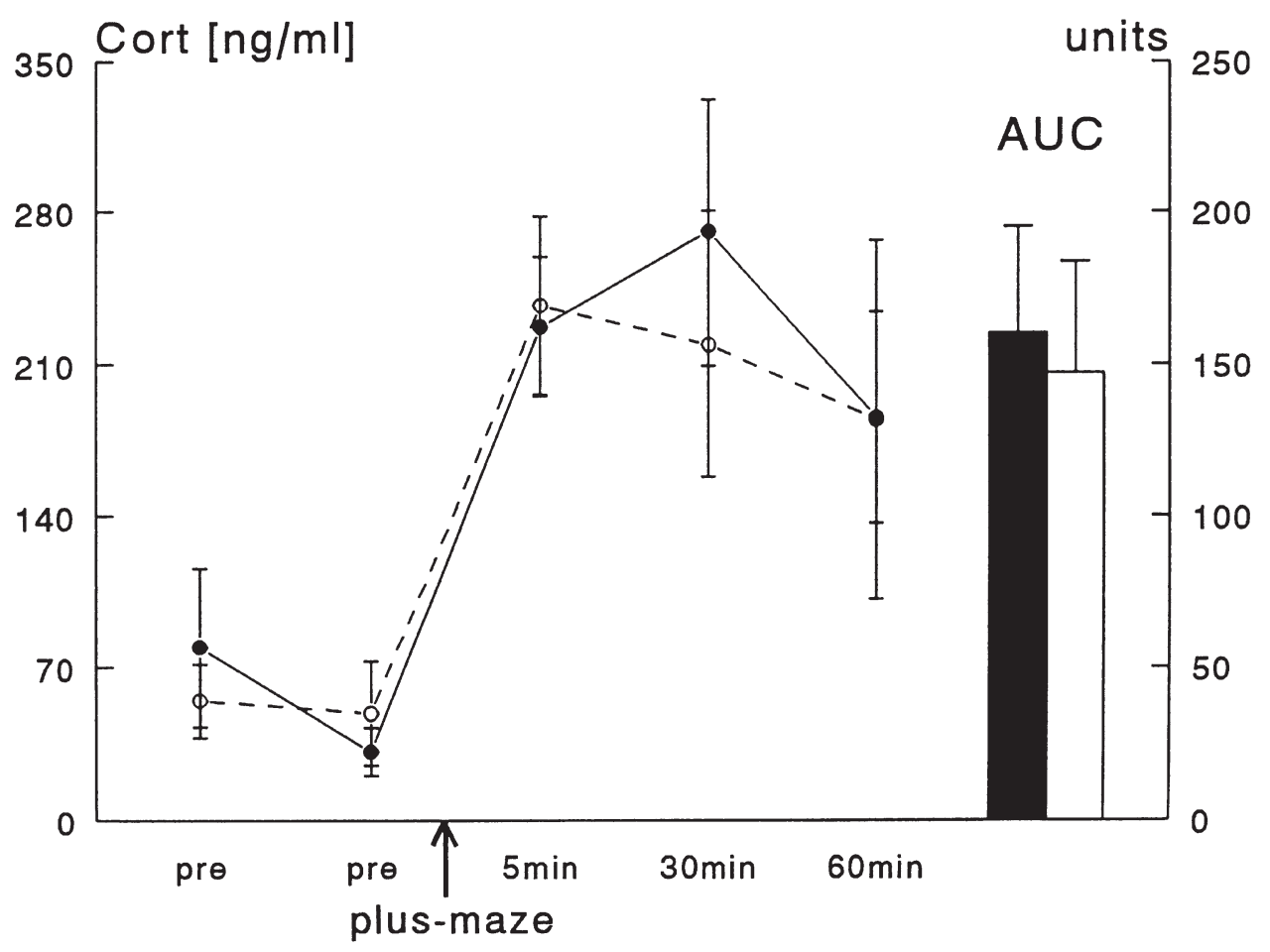

Figure 6. ACTH (upper panel) and corticosterone (Cort; lower panel) concentrations in plasma samples collected from male HAB and LAB rats $(n=6$ per group) in their home cage before (pre) and after exposure to the elevated plus-maze for $5 \mathrm{~min}$. AUC: area under the curve (for details see Results section).

bution of the sympathetic nervous system to the line differences was provided by biotelemetrical recording over several days. No over-all difference between HAB and $\mathrm{LAB}$ rats was found in body temperature, locomo- tor activity, food and water intake, and their respective circadian rhythms (Figure 3), indicating that the profound line differences in anxiety-related and stresscoping behavior are not accompanied by (or even at- 
tributable to) differences in basic physiological parameters. This finding indicates that rats from the LAB line, which have been shown to display a higher activity than HAB rats in an open field (Liebsch et al. 1998), do not differ generally in their spontaneous home cage locomotor activity. This is in line with findings in the THE/TLE strains (Fujita et al. 1994) and in Roman highand low-avoidance rats that also display differential activity in an open field (Gentsch et al. 1981), but only a trend toward higher nighttime activity in high avoidance rats when measured telemetrically in the home cage (Meerlo et al. 1997). It also supports the concept of "reactive" versus "spontaneous" locomotor activity (Courvoisier et al. 1996; Gentsch et al. 1991). Interestingly, and in contrast to other studies that have demonstrated long-term changes in the amplitude of the circadian rhythm in body temperature, activity, and food intake following a 1-h social defeat (Meerlo et al. 1996, 1997) or in activity and water intake after electric tailshock (Scott et al. 1996), the amplitude of the diurnal rhythm of all parameters measured in the present experiment had already returned to baseline values on the day following social defeat (Figure 3). However, increased daytime body temperature (Figure 3A) and decreased nighttime locomotor activity (Figure 3B), as reported in the above-mentioned studies (Meerlo et al. 1996; 1997), were found on the actual days of exposure to social defeat and, to a lesser extent, after plus-maze exposure. Possibly, the impact of a 10-min defeat experience (and even less, a plus-maze exposure) is not stressful enough to induce long-lasting changes in physiological rhythms.

Whereas no line differences in stress-induced alterations in diurnal body temperature and activity rhythms were found, HAB and LAB rats differed in acute, shortterm changes in both parameters in response to mild (plus-maze) and more severe (social defeat) emotional stress. Following plus-maze exposure, locomotor activity scores during the first $4 \mathrm{~h}$ post stress were higher in $\mathrm{LAB}$ than in $\mathrm{HAB}$ rats (Figure 5), contrary to the changes in body temperature that, after an initial rise during the first $45 \mathrm{~min}$ poststress, decreased again in $\mathrm{LAB}$ rats but remained elevated for almost $3 \mathrm{~h}$ after stress in HAB animals, despite lower activity during this time (Figures 4 and 5A). This finding confirms evidence that changes in body temperature and locomotor activity following stress exposure are not necessarily directly linked but may be caused by differences in (emotional) appraisal of the stress situation (Meerlo et al. 1996). The marked behavioral differences between $H A B$ and LAB rats on the plus-maze clearly confirm this notion, but in the social defeat paradigm, no differences in behavioral reactions of $\mathrm{HAB}$ and $\mathrm{LAB}$ rats to the attacks of the residents were observed. However, the intensity of aggression displayed by the residents probably did not leave much room for variations in behavioral reac- tivity, possibly suggesting some kind of "ceiling effect" in response to this stressor.

After a preliminary experiment on a small number of animals from the $\mathrm{F} 4$ generation, indicating similar basal but higher stress-induced ACTH and corticosterone plasma levels in HAB rats as compared to LAB animals (unpublished data), we had to accept that, in the F6 generation, this difference in ACTH response to stress exposure failed to reach statistical significance. However, as seen in Figure 6, there is a trend toward higher HPA activity to mild emotional stress (plus-maze exposure) in $\mathrm{HAB}$ as compared to LAB rats. Hence, selection for high levels of plus-maze anxiety might not necessarily co-select neuroendocrine reactivity, because no correlation was found between behavioral measures of anxiety in the plus-maze test and the increase in ACTH and corticosterone concentrations in both lines. Although exposure to the elevated plus-maze stimulates the HPA axis (File et al. 1994; Neumann et al. 1998), anxiety-related behavior on the plus-maze has also been demonstrated to be independent of an HPA axis activation (Pich et al. 1993). A dissociation between emotionality and HPA reactivity similar to the present results has also been found in the Syracuse (Brush 1991) and Maudsley (Abel 1991) rats, suggesting that endocrine correlates may not be tightly linked to the respective emotionality genotype. On the other hand, clear associations between behavioral and neuroendocrine stress reactivity have been demonstrated in the Roman high- and low-avoidance rats, but these rats have also been shown to differ in basal HPA activity and pituitary sensitivity to CRH (Walker et al. 1989; 1992), which is not the case in the HAB and LAB lines (see Table 1). Interestingly, as indicated by the SEM values in Figure 6, there were some individuals in the $\mathrm{HAB}$ group showing extremely high ACTH levels after plusmaze exposure, and some responded only with a small increase; whereas, the rats within the LAB group displayed a more homogenous response pattern. Thus, HAB rats could possibly be split into two different types of responders in terms of HPA activation, similar to the paradoxically "stress nonresponsive" subgroups found in rats subjected to chronic social stress (Albeck et al. 1997; Blanchard et al. 1995), but further studies are clearly needed to test this assumption. In this context, it is of interest to note that psychiatric patients suffering from anxiety/depression show a varying responsiveness of their HPA axis to stimulation (Platt et al. 1994; Kim et al. 1995).

The fact that the corticosterone response to plusmaze exposure was less dissimilar in $\mathrm{HAB}$ and $\mathrm{LAB}$ rats than the ACTH secretion, in concert with a similar adenohypophysial responsiveness to CRH (Table 1) and similar adrenal weights (data not shown), may indicate a more pronounced contribution of the sympathoadrenal system in LAB rats, consistent with the general view 
that animals with active behavioral strategies are more sympathetically dominated (Bohus et al. 1987; Johnson et al. 1992). Following exposure to a more severe stressor (forced swimming), the difference in $\mathrm{ACTH}$ and corticosterone increase was less evident than after plusmaze testing (Table 1), again suggesting a "ceiling effect" and consistent with differential HPA reactivity to mild (novel environment), but not to more severe (immobilization, footshock) stressors in the Roman rats (Gentsch et al. 1988; Walker et al. 1989).

In summary, the results of the present study add some important findings to the characterization of the $\mathrm{HAB}$ and LAB rats. Differential sensitivity of anxietyrelated behavior, but not coping strategy, to anxiolytic treatment, as well as the absence of general differences in physiological parameters underline the selectivity of the breeding process. Throughout all the experiments, line differences seem to be most pronounced under conditions of mild emotional stress-the selection criterion. As far as the results obtained so far indicate, our lines fit well into the general picture that emerges from the literature on selective breeding projects. It seems that such selection has mostly resulted in common characteristics that differentiate the lines/strains in emotionality or emotional reactivity and general coping style, with high levels in the former associated with rather passive strategies in the latter (Bohus et al. 1987; Brush 1991; Castanon and Mormède 1994; Cools et al. 1993; Gentsch et al. 1988; Steimer et al. 1997; Walker et al. 1992). The endocrine data, on the other hand, are sometimes contradictory (Abel 1991; Brush 1991; Courvoisier et al. 1996), indicating that the activity of the HPA system is not necessarily tightly linked to the type of behavioral reactivity in stressful situations.

\section{ACKNOWLEDGMENTS}

The authors thank Patrick Lörscher, Julia Ganster, Gabi Kohl, and Thomas Pohl for expert technical assistance, and Drs. Alexander Yassouridis and Mario Engelmann for helpful advice concerning statistical analysis of the biotelemetry data. This study was supported by the Deutsche Forschungsgemeinschaft.

\section{REFERENCES}

Abel EL (1991): Behavior and corticosteroid response of Maudsley reactive and nonreactive rats in the open field and forced swimming test. Physiol Behav 50:151-153

Abel EL (1994): A further analysis of physiological changes in rats in the forced swim test. Physiol Behav 56:795-800

Albeck DS, McKittrick CR, Blanchard DC, Blanchard RJ, Nikulina J, McEwen BS, Sakai RR (1997): Chronic social stress alters levels of corticotropin-releasing factor and arginine vasopressin mRNA in rat brain. J Neurosci 17:4895-4903
Antoni FA (1986): Hypothalamic control of adrenocorticotropin secretion: Advances since the discovery of 41-residue corticotropin-releasing factor. Endocr Rev 7:351-378

Armario A, Galvadà A, Martí O (1988): Forced swimming test in rats: Effect of desipramine administration and the period of exposure to the test on struggling behaviour, swimming, immobility, and defecation rates. Eur J Pharmacol 158:207-212

Armario A, Gavaldà A, Martí J (1995): Comparison of the behavioral and endocrine response to forced swimming stress in five inbred strains of rats. Psychoneuroendocrinology 20:879-890

Blanchard DC, Spencer RL, Weiss SM, Blanchard RJ, McEwen BS, Sakai RR (1995): Visible burrow system as a model of chronic social stress: Behavioral and neuroendocrine correlates. Psychoneuroendocrinology 20: 117-134

Bohus B, Benus RF, Fokkema DS, Koolhaas JM, Nyakas C, van Oortmerssen GA, Prins AJA, de Ruiter AJH, Scheurink AJW, Steffens AB (1987): Neuroendocrine states and behavioral and physiological stress responses. Prog Brain Res 72:57-70

Boissy A (1995): Fear and fearfulness in animals. Quart Rev Biol 70:165-191

Brush FR (1991): Genetic determinants of individual differences in avoidance learning: Behavioral and endocrine characteristics. Experientia 47:1039-1050

Castanon N, Mormède P (1994): Psychobiogenetics: Adapted tools for the study of the coupling between behavioral and neuroendocrine traits of emotional reactivity. Psychoneuroendocrinology 19:257-282

Chaouloff F, Castanon N, Mormède P (1994): Paradoxical differences in animal models of anxiety among the Roman rat lines. Neurosci Lett 182:217-221

Chapouthier G, Bondoux D, Martin B, Desforges C, Launay J-M (1991): Genetic differences in sensitivity to $\beta$-carboline: Evidence for the involvement of brain benzodiazepine receptors. Brain Res 553:342-346

Clément Y, Proeschel M-F, Bondoux D, Girard F, Launay J-M, Chapouthier G (1997): Genetic factors regulate processes related to anxiety in mice. Brain Res 752:127-135

Commissaris RL, Harrington GM, Altman HJ (1990): Benzodiazepine anticonflict effects in Maudsley reactive (MR/Har) and nonreactive (MNR/Har) rats. Psychopharmacology 100:287-292

Cools AR, Brachten R, Heeren D, Willemen A, Ellenbroek B (1990): Search after neurobiological profile of individualspecific features of Wistar rats. Brain Res Bull 24:49-69

Cools AR, Rots NY, Ellenbroek B, de Kloet ER (1993): Bimodal shape of individual variation in behavior of Wistar rats: The overall outcome of a fundamentally different make-up and reactivity of the brain, the endocrinological, and the immunological system. Neuropsychobiology 28:100-105

Courvoisier H, Moisan M-P, Sarrieau A, Hendley ED, Mormède P (1996): Behavioral and neuroendocrine reactivity to stress in the WKHA/WKY inbred rat strains: A multifactorial and genetic analysis. Brain Res 743:77-85

Curé M, Rolinat JP (1992): Behavioral heterogeneity in Sprague-Dawley rats. Physiol Behav 51:771-774 
Dawson GR, Tricklebank MD (1995): Use of the elevated plus maze in the search for novel anxiolytic agents. TIPS 16:33-37

Fernandez-Teruel A, Escorihuela RM, Tobena A, Driscoll P (1991): Stress and putative endogenous ligands for benzodiazepine receptors: The importance of characteristics of the aversive situation and of differential emotionality in experimental animals. Experientia 47:1051-1056

File SE, Zangrossi Jr H, Sanders FL, Mabbutt PS (1994): Raised corticosterone in the rat after exposure to the elevated plus-maze. Psychopharmacology 113:543-546

Fujita O, Annen Y, Kitaoka A (1994): Tsukuba high- and lowemotional strains of rats (Rattus norvegicus): An overview. Behav Genet 24:389-415

Gendron CM, Brush FR (1996): The effects of extended training and acute administration of an anxiolytic on avoidance learning and intertrial responding in the Syracuse strains of rats. Behav Genet 26:575-580

Gentsch C, Lichtsteiner M, Feer H (1981): Locomotor activity, defecation score, and corticosterone levels during an openfield exposure: A comparison among individually and group-housed rats, and genetically selected rat lines. Physiol Behav 27:183-186

Gentsch C, Lichtsteiner M, Feer H (1988): Genetic and environmental influences on behavioral and neurochemical aspects of emotionality in rats. Experientia 44:482-490

Gentsch C, Lichtsteiner M, Feer H (1991): Genetic and environmental influences on reactive and spontaneous locomotor activities in rats. Experientia 47:998-1008

Green S, Hodges H (1991): Animal models of anxiety. In Willner P (ed), Behavioural Models in Psychopharmacology. Cambridge, UK, Cambridge University Press, pp 21-49

Griebel G (1995): 5-Hydroxytryptamine-interacting drugs in animal models of anxiety disorders: More than 30 years of research. Pharmacol Therap 65:319-395

Handley SL, McBlane JW, Critchley MAE, Njung'e K (1993): Multiple serotonin mechanisms in animal models of anxiety: Environmental, emotional and cognitive factors. Behav Brain Res 58:203-210

Hess J, Lesser D, Landgraf R (1992): Vasopressin and oxytocin in brain areas of rats selectively bred for differences in behavioral performance. Brain Res 569:106-111

Holsboer F, Gerken A, Stalla GK, Muller OA (1987): Blunted aldosterone and ACTH release after CRH administration in depressed patients. Am J Psychiat 144:229-231

Johnson EO, Kamilaris TC, Chrousos GP, Gold PW (1992): Mechanisms of stress: A dynamic overview of hormonal and behavioral homeostasis. Neurosci Biobehav Rev 16:115-130

Kim KD, Kim BL, Yu BH, Hong KS, Ritchie J, Austin S, Carroll BJ (1995): Rate-sensitive glucocorticoid feedback inhibition in normal humans and depressed patients. Soc Neurosci Abstr 21:873

Lader M (1991): Animal models of anxiety: A clinical perspective. In Willner P (ed), Behavioural Models in Psychopharmacology. Cambridge, UK, Cambridge University Press, pp 76-88

Lahmame A, Grigoriadis DE, De Souza EB, Armario A (1997): Brain corticotropin-releasing factor immunoreactivity and receptors in five inbred rat strains: Relation- ship to forced swimming behavior. Brain Res 750:285292

Liebsch G, Montkowski A, Holsboer F, Landgraf R (1998): Behavioral profiles of two Wistar rat lines selectively bred for high- or low-anxiety-related behavior. Behav Brain Res 94:301-310

Martí J, Armario A (1993): Effects of diazepam and desipramine in the forced swimming test: Influence of previous experience with the situation. Eur J Pharmacol 236:295-299

Meerlo P, de Boer SF, Koolhaas JM, Daan S, van den Hoofdakker RH (1996): Changes in daily rhythms of body temperature and activity after a single social defeat in rats. Physiol Behav 59:735-739

Meerlo P, Overkamp GJF, Koolhaas JM (1997): Behavioural and physiological consequences of a single social defeat in Roman high- and low-avoidance rats. Psychoneuroendocrinology 22:155-168

Miczek KA (1979): A new test for aggression in rats without aversive stimulation: Differential effects of d-amphetamine and cocaine. Psychopharmacology 60:253-259

Mormède P, Lemaire V, Castanon N, Dulluc J, Laval M, Le Moal M (1990): Multiple neuroendocrine responses to chronic social stress: Interaction between individual characteristics and situational factors. Physiol Behav 47:1099-1105

Neumann I, Johnstone H, Hatzinger M, Liebsch G, Shipston M, Russell JA, Landgraf R, Douglas AJ (1998): Attenuated neuroendocrine responses to emotional and physical stressors in pregnant rats involve adenohypophysial changes. J Physiol 508.1:289-300

Overstreet DH, Rezvani AH, Janowski DS (1992): Maudsley reactive and nonreactive rats differ only in some tasks reflecting emotionality. Physiol Behav 52:149-152

Overstreet DH, Rezvani AH, Knapp DJ, Crews FT, Janowski DS (1996): Further selection of rat lines differing in 5-HT-1A receptor sensitivity: Behavioral and functional correlates. Psychiat Genet 6:107-117

Paré WP (1992): The performance of WKY rats on three tests of emotional behavior. Physiol Behav 51:1051-1056

Pellow S (1986): Anxiolytic and anxiogenic drug effects in a novel test of anxiety: Are exploratory models of anxiety in rodents valid? Meth Find Exp Clin Pharmacol 8:557565

Pich EM, Heinrichs SC, Rivier C, Miczek KA, Fisher DA, Koob GF (1993): Blockade of pituitary-adrenal axis activation induced by peripheral immunoneutralization of corticotropin-releasing factor does not affect the behavioral response to social defeat stress in rats. Psychoneuroendocrinology 18:495-507

Platt JE, Simkowitz P, Silva R, Schwitzer J, Friedhoff JA (1994): Responsiveness to stress in major depression. Program and Abstracts, First World Congress on Stress 1:69

Porsolt RD, LePichon M, Jalfre M (1977): Depression: A new animal model sensitive to antidepressant treatment. Nature 266:730-732

Prasad A, Henry M, Prasad C (1996): Heterogeneity in the performance of outbred Sprague-Dawley rats in an elevated-plus maze test: A possible animal model for anxiety disorder. Life Sci 59:1499-1506

Prasad A, Imamura M, Prasad C (1997): Dehydroepiandro- 
sterone decreases behavioral despair in high- but not low-anxiety rats. Physiol Behav 62:1053-1057

Ramos A, Berton O, Mormède P, Chaouloff F (1997): A multiple-test study of anxiety-related behaviors in six inbred rat strains. Behav Brain Res 85:57-69

Robertson HA, Martin IL, Candy JM (1978): Differences in benzodiazepine receptor binding in Maudsley reactive and Maudsley nonreactive rats. Eur J Pharmacol 50:455457

Rodgers RJ, Cao B-J, Dalvi A, Holmes A (1997): Animal models of anxiety: An ethological perspective. Braz J Med Biol Res 30:289-304

Schöbitz B, Pezeshki G, Pohl T, Hemmann U, Heinrich PC, Holsboer F, Reul JMHM (1995): Soluble interleukin-6 receptor augments central effects of interleukin-6 in vivo. FASEB J 9:659-664

Scott PA, Cierpial MA, Kilts CD, Weiss JM (1996): Susceptibility and resistance of rats to stress-induced decreases in swim-test activity: A selective breeding study. Brain Res 725:217-230

Spanagel R, Montkowski A, Allingham K, Stöhr T, Shoaib M, Holsboer F, Landgraf R (1995): Anxiety: A potential predictor of vulnerability to the initiation of ethanol selfadministration. Psychopharmacology 122:369-373

Steimer T, Driscoll P, Schulz PE (1997): Brain metabolism of progesterone, coping behavior, and emotional reactivity in male rats from two psychogenetically selected lines. J Neuroendocrinol 9:169-175

Stephens DN, Andrews JS (1991): Screening for anxiolytic drugs. In Willner P (ed), Behavioural Models in Psychopharmacology. Cambridge, UK, Cambridge University Press, pp 50-75

Tesser A (1993): The importance of heritability in psychological research: the case of attitudes. Psychol Rev 100:129-142
Thierry B, Steru L, Chermat R, Simon P (1984): Searchingwaiting strategy: A candidate for an evolutionary model of depression? Behav Neural Biol 41:180-189

Tyrer P (1992): Anxiety and depression: A clinical profile. In Elliott JM, Heal DJ, Marsden CA (eds), Experimental Approaches to Anxiety and Depression. Chichester, UK, John Wiley \& Sons, pp 9-23

Vale W, Spiess J, Rivier C, Rivier J (1981): Characterization of a 41-residue ovine hypothalamic peptide that stimulates secretion of corticotropin and $\beta$-endorphin. Science 213: 1394-1397

Viglinskaya IV, Overstreet DH, Kashevskaya OP, Badishtov BA, Kampov-Polevoy AB, Seredenin SB, Halikas JA (1995): To drink or not to drink: Tests of anxiety and immobility in alcohol-preferring and alcohol-nonpreferring rat strains. Physiol Behav 57:937-941

Walker C-D, Aubert ML, Meaney MJ, Driscoll P (1992): Individual differences in the activity of the hypothalamuspituitary-adrenocortical system after stressors: Use of psychogenetically selected rat lines as a model. In Driscoll P (ed), Genetically Defined Animal Models of Neurobehavioral Dysfunctions. Boston, Birkhäuser, pp 276-296

Walker C-D, Rivest RW, Meaney MJ, Aubert ML (1989): Differential activation of the pituitary-adrenocortical axis after stress in the rat: Use of two genetically selected lines (RLA and RHA) as a model. J Endocrinol 123:477485

Zhukov DA, Vinogradova KP (1994): Inescapable shock induces the opposite changes of the plus-maze test behavior in rats with divergent coping strategy. Physiol Behav 56:1075-1079

Zuckerman M (1993): P-impulsive sensation seeking and its behavioral psychophysiological and biochemical correlates. Neuropsychobiology 28:30-36 